DOI https://doi.org/10.18551/rjoas.2017-06.22

\title{
FOREIGN AND DOMESTIC INVESTOR BEHAVIOR: A SYNTHESIS OF BEHAVIORAL BIAS IN BEHAVIORAL FINANCE
}

\author{
Sakir A.* \\ Faculty of Economics and Business, University of Syiah Kuala; \\ Doctoral Degree Program in Management, Faculty of Economics and Business, \\ University of Brawijaya, Indonesia \\ Salim Ubud, Djumahir, Djazuli Atim \\ Faculty of Economics and Business, University of Brawijaya, Indonesia \\ *E-mail: asakirih@yahoo.com
}

\begin{abstract}
This literature review aims to synthesize various research findings studying the foreign investor's superiority to the domestic. This synthesis was conducted by combining numerous findings of the research that has been performed by specialty researchers relating to the investor behavior at capital market. There were four main articles that were ran into or contemplated with several behavioral biases in behavioral finance like self-attribution bias, illusion of control bias, conservative bias, ambiguity of eversion bias, and endowment bias. In addition, it was also connected to the phenomenon of the existence of foreign investor at capital market that is extremely dominant. However, the research findings of the cause of foreign investors' superiority to the domestic at capital market are not uniform among the researchers. It causes by several factors like the aggressiveness of investor, information superiority, poor timing, non-egalitarian investor distribution, and the power of psychological dimension of investment among the investors. For that reason, there is an opportunity to the next researchers to study this inconsistent result in advance.
\end{abstract}

\section{KEY WORDS}

Investor behavior, behavioral finance, behavioral bias.

Research result synthesis and this behavioral finance theory involve different finding why foreign and domestic investors' performance is different if related to the several kinds of prominent behavioral bias. This study refers to the four main articles pertaining to that bias that is consisted of one main journal and three complimentary journals. Every synthesis of this behavioral bias will be ran into the existing theory which is connected to the behavioral finance theory and the research finding from a well-known researcher, so that every discussion will be directly connected to the investor behavioral bias.

The study of investor behavior in the decision making of behavior and emotional-based investment (irrational perspective) start to get attention since 1979 when Kahnemen and Tversky through the prospect theory succeeded to shows empirical relations between the psychological and economics theory. Explicitly, they criticized the use of Expected Utility Theory as a mainstream in explaining the decision making process. The study conducted by Kahneman and Tversky (1979) then became a trigger for more advanced economics research that is based on the irrational perspective for the future development. The explanation above indicates that irrational perspective was developed to give better explanation and understanding of the psychological bias happens at capital market, which cannot be explained by rational perspective. This happens since in addition to using "ratio", investor also use "emotional" in making decision for investment. Both complete each other in order to form short-term reaction or long-term behavior of human being, at which at a particular time ratio would dominate investor in making decision of investment and in another way emotional would be possible to do (Wendy, 2012 and Asri, 2013) In line with this idea, 
Schinckus (2011) stated that behavioral finance was a new approach that learnt financial reality by including investment psychological dimension.

The main article becoming reference of this finance behavioral synthesis is adapted from Agarwal et al. (2009) entitled "Why do foreign investors underperform domestic investors in trading activity? Evidence from Indonesia. And the others complementary journals are adapted from (1) Dvorak (2005) entitled "Do domestic investors have an information advantage? Evidence from Indonesia", (2) Choe et al.(2005) entitled "Do domestic investors have an edge? The trading experience of foreign investor in Korea"; and (3) Kalev et al. (2008) entitled "Foreign versus local investors: Who knows more? Who make more?".

Foreign and Domestic Investors' Performance. In this first article, Agarwal et al.(2009) examined why foreign investors' performance was lower than the domestic at the stock trading activity in Indonesia Stock Exchange (BEI). This study aims to deeply examine why foreign investors' performance are lower than the domestic. The main background of this study appears since the previous various research findings stating that foreign investor has lower position than the domestic like the study conducted by Dvorak (2005) and Choe (2005). According to Dvorak, previous researchers have found that local investors were more superior to the foreign since they get more information than the foreign. While Choe et al. said that mentioning domestic investor to be more superior at trading activity in Korea Exchange was since the poor timing of foreign investor trading. On the other hand, Agarwal (2009) stated that the aggressiveness of foreign investors has made them get higher price both when they buy and sell stock. For that reason, Agarwal interested in conducting research again in Indonesia Stock Exchange to find out what exactly make domestic investors more superior than the foreign since all this time can be known that foreign investor was more superior than the domestic, both technological sophistication and experience, but the previous findings shows the opposite that domestic investor was more superior, thus this becomes a trigger why Agarwal want to conduct a study again.

Self-Attribution Bias. Having been reviewed from the aspect of behavioral finance theory especially refers to the aspect of investor bias type from the behavioral finance book written by Pompian (2006), particularly for kind of behavioral bias, then the research result conducted by Agarwal further involves self-attribution bias, that is, making foreign investor more aggressive to perform trading. Aggressiveness of foreign investors points them to make a hasty decision to buy let alone the price can go down and sell whereas the price can go up, thus return they get is smaller than the domestic. Consequently, as what Pompian said that this bias results to the foreign investor that make them over confident in the trading behavior, thus this bias endanger the management of foreign investor's treasure itself as they are too aggressive, it is surely affected on their bad performance, thus the domestic investor was more superior since they are not as aggressive as foreign investor. Even though the term of self-attribution means to the individual (investor) tendency assuming that the success s/he gets comes from his/her ability in investment, and if it is fails s/he will search for scapegoat or blame someone or something else. However, a fact of behavioral aspect is that investors who are susceptible or experience this bias then become aggressive, according to Agarwal, this happens to the foreign investor. Pompian also stated to always remember old proverb applied in Wall Street investor, namely: "Don't confusing your mind with the market going up leaf" meaning that as an investor we are not allow to be over confident with market condition going up too higher as capital market is fluctuated. For that reason, being too aggressive like foreign investor is not good enough since foreign investor is under the domestic investor's performance in Indonesian Stock Exchange.

Technically, self-attribution concerns cognitive phenomenon at which people address failure to the factors of situation while their success is a factor that has been determined or dispositional. Self-attribution bias can be divided into two, firstly, self-irrational bias that shows people's tendency to claim the level of belief irrationality of their success. Secondly, self-protection bias shows a proper effect, proper denial and responsibility of failure. Yet, thing needs to pay attention is as this cognitive bias connected to the emotional explanation, then it will be hard to make sure which type of bias works on a particular situation. 
Illusion of Control Bias. Like Pompian said, foreign investor behavior which is too aggressive relates to the illusion of control bias. Illusion of control bias illustrates a tendency of human being to believe that they can control something or influence a behavior, whereas in fact it cannot be controlled. This can be seen for instance at games or gambling in Las Vegas Casinos. For that reason, effect of this bias also causes foreign investors at Indonesia Stock Exchange becomes more aggressive, then they only put a little attention in stocks trading or it can be said that they are impatient compared to the domestic behavior. But then it does not mean that investor are not allowed to be aggressive, yet they should consider that capital market needs a timing strategy, it means that there is time when we have to go out of market (sell) and go in of market (buy).

Argarwal's finding is briefly explained follows. Agarwal's research comes between foreign and domestic investors' performance written in Journal of Financial Markets along with his team in 2009. In this research, Agarwal and his team studied much more issuers-i.e. 100 issuers white longer duration started from May 1995 to May 2003. Saying yes to the study conducted by Dvorak (2005), Agarwal stated that compared to domestic investor, the foreign pays $9 \%$ higher when buying and accepting $14 \%$ lower when selling.

Conservative Bias. The different of Dvorak and Argawal's finding is that Argawal does not agree about the information superiority becomes cause of difference. They said that foreign investors are more aggressive than the domestic. Foreign investors want to finish their transaction faster, and then they have to buy with higher price and sell with the lower price. This difference of cost makes their short-term performance worse than domestic investor. It is like runner illustrated that domestic investor is better at sprint (100 meters) while foreign investor good at marathon $(5-10 \mathrm{~km})$ this is similar to conservative bias. Conservative bias is kind of cognitive bias that is a mental process at which people put their previous views or estimation admitting new information. Having been estimated that an investor receives bad news about company profit and this news negatively opposite to another profit estimation issued previous month. Bias conservative can result investor have less reaction to new information, questioning about impression coming from previous estimation is better than acting to the updated information. It is important to note that conservative bias causes representativeness bias conflict. In this term, people act exaggeratedly to the new information. People obviously can show those two biases: If the data seems appropriate or represented and the model is based, then people can be overloaded with the data in conformity with the representativeness bias.

This is in line with the research results of Dvorak (2005), but he stated that the advantage of the domestic rather than foreign investors because domestic investors have information superiority compared to the foreign, which caused domestic investors in Indonesia Stock Exchange has no language and cultural constraints to invest shares. Brief research results conducted by Dvorak (2005) regarding information superiority. Emerging capital markets especially in developed countries, behavioral finance is an interesting study because it is often assumed that foreign investors are more skilled in investing because they have an advantage in their investment experience and skills. They are considered to have excellence information, so that it is more superior in assessing the prospect of a country as well as company fundamentals. In contrast, domestic investors are often considered less confident and often follow the strategy of foreign investors. As a result, foreign investors have the advantage of being able to enter and exit the stock first. However, there is a conflicting argument that domestic investors are more superior because they have local information unknown by foreign investors. In addition, they have no language and culture problem. In terms of digesting information, then these foreign investors are said to experience a conservative bias, in this conservative bias investors are reacting to new information, they often do it too slowly. For example, when stock prices are expected to fall, then we are too late to sell them because the conservative investor could have made it too slow to sell them.

Some scholars have tried to prove which opinions are more acceptable. From various research results, one of them can be seen in the article entitled Journal of Finance written by Tomas Dvorak (2005). The results of this study record every transaction on 30 shares of Indonesia Stock Exchange that is the most liquid during January 1998 until December 2001. 
There are three important findings from this Dvorak study that uses 7.4 million transactions. Firstly, without distinguishing the brokerage firm used, domestic investors in Indonesia Stock Exchange is more superior. During the research period, they made a profit of Rp 4 trillion more than foreign investors. It means that domestic investors have superior information to the foreign. Secondly, there is a difference in performance between investors who use local and foreign brokers. Of the 200 brokerage firms surveyed by Dvorak, 179 are locally owned and the rest are foreign. In addition to run order from investor, brokerage firm also as an investment consultant to the client. In general, foreign investors at BEI use foreign brokers, while the domestic uses local brokers.

Dvorak also found that compared to the local brokerage clients, foreign brokerage clients enjoy higher long-term benefits, but medium-term profits (intramonth) and lower intraday. Meaning that local brokerage clients have short-lived information advantage, but foreign brokerage clients are smarter in choosing good fundamental stocks (long-term winners). Thirdly, domestic investors who use global brokers have the best performance among all investors. This identifies that the combination between local information superiority and the expertise of global brokers is able to create superior performance at BEl.

Detail information from the results of Dvorak's (2005) study explain that obtained the most powerful evidence that domestic investors have information superiority compared to the foreign in Indonesia stock exchange. The fact is that foreign investors are systematically trading at a daily price which is worse than domestic investors. It is also proved that domestic investors are encouraged to buy before the positive return (price goes up) of the information they get from the information revealed later. Finally, the purchase of domestic investors contains more information than the foreign.

Ambiguity of Aversion Bias. The direction of change in asymmetric information over time raises an ambiguity. This is what Pompian says as the ambiguity of aversion bias, at which attempts to buy shares that they know more than they do not yet know. Daily prices, at which foreign investors trade, have substantially deteriorated in recent years. In contrast, the superior ability of domestic investors to predict future returns has disappeared in the latest sub-period. The purchase of domestic investors more informed than the foreign is stable over time.

People do not like to gamble when probability distribution seems uncertain. In general, people hesitate in situations of confusion or tenderness, this trend is known as ambiguity aversion bias. Avoidance of ambiguity arises in a wide variety of contexts. For example, a researcher may ask a subject to estimate the probability that the team's certainty will win the next university's football competition. Subjects can estimate 50 percent chance of success.

Compared to Korea, asymmetric information in Indonesian capital market is not as severe as in Korea or also known as term home bias. In particular, it was not found that domestic investors bought 5 days before negative returns or sales of foreign investors were more informed than the domestic. Foreign investors in Indonesia trade when prices are worse than foreign investors in Korea.

As the results of research by Choe et al. (2005), found that foreign investors trade at an uglier price when they sell than when they buy. This finding is the same for both countries supporting that this reflects the general phenomenon better than the special features of a capital market or other.

Meanwhile, compared to the Sheasholes' (2000) towards data in Taiwan, it was found that foreign investors bought 22 days before the good news was positive but statistically weak. In contrast, the Sheaholes findings stated that foreign investors' purchases 22 days before bad news were positive and statistically significant. Therefore, domestic investors have superiority information. Both Choe and Sheasholes' methods from previous research have given the same conclusions when the data applied in Indonesia. This supports that asymmetric information in Taiwan may indeed be different from in Korea and Indonesia.

By considering the timing strategy, then what has been found by Choe et al. (2005) in a research conducted in Korea is true. It stated that investor in Korea, for instance domestic investor is more superior since the poor timing owned by the foreign in investing, meaning that exit and enter of the market is less appropriate than Korean investors itself, so foreign 
investors in Korea are also under domestic investors. Choe's research aims to investigate whether domestic investors have more side to foreign investors in domestic share trading. His background in doing this research is due to inconsistent results /views from previous research where there is a view that domestic investors have superiority to trade their own shares in their own country over foreign investors because they have information superiority and other factors such as regulatory which is more tolerant to domestic investors, even bias against foreign investors happens. It is seen that domestic investors have a higher side than the foreign, or also known as a home bias.

Judging from the behavioral finance theory, home bias is related to ambiguity aversion bias. This behavioral bias is one's confusion in ambiguity situations, or a situation where if one investor is more competent about domestic share than the foreign, then s/he will buy more domestic stocks, because their knowledge of domestic stock is superior to the foreign. This is called the effect of competence in stock trading, and vice versa if a person feels unfamiliar about something investing the asset then he will reduce the purchase of the asset. Therefore, in this ambiguity aversion bias is known as "unknown, unloved". This study was conducted at Korea Exchange by taking all stock trading data from the period of 2nd December 1996 to 30th November 1999.

The findings of Choe et al stated that foreign investment managers pay more than the domestic when they buy stocks and have received less when they sell shares during big and medium trading. For the average sample of weighted average of medium-sized is obtained weakness on foreign investment managers of 21 percent for purchases, and 6 percent for sales. There is also some evidence that individual domestic investors have a side that exceeds foreign investors, due to the fact that prices move very opposite to foreign investors rather than the domestic before trading. This is in more detail due to three factors, namely: firstly, foreign investors are more impatient, or trade when liquidity is lower, so they pay more for provider liquidity. Secondly, foreign investors know better, so the influence of their trade has a bigger permanence. Thirdly, foreign investors trade after prices are ready to move against them.

The third complimentary journal synthesized was written by Kalev et al.(2008) entitled "Foreign versus local investors: Who knows more? Who makes more? Basically, the purpose of this study was to examine the asymmetric characteristics of information among foreign and domestic investors in Helsinki Stock Exchange (HEX) during the period 1994 -2004. Here Kalev et al. distinguishes the asymmetric characteristics of information by blocking shares of single listed (listed on only one exchange) and cross listed, and commonly known as either international/global stock. There are 35 samples from the best stocks in Finland which are sampled for this research. This third journal is more concerned with ambiguity bias or home bias, especially with regard to opinions in the literature review of a journal which says that there are two different literature explanations from this study originally started. Firstly, local investors prefer and claim that they have fewer hurdles than the foreign in accessing local company data about the company's specific information (Hau, 2001; Dvorak, 2005; Brennan and Cao, 1997; Parwada et al., 2007 in Kalev, 2008). Another explanation is that it supports the argument that says that foreign investors are more sophisticated investors with superior skills that can help to analyze market conditions and make more informed decisions.

The research results of Kalev et al (2008) found that the study supported empirically asymmetric hypotheses of information among local and foreign investors. It is found that shares listed on only one exchange (single listed) are exclusive to local investors and their ownership level is dominant. However, in cross-listed shares, foreign investors' ownership can be compared to their local partners. Internationally-renowned shares (such as Nokia) are the exception since they are owned by foreign investors which almost 90 percent of average is the sample period. The same pattern is also shown in trade statistics. Thus, foreign investors invest and trade further for more transparent shares of information as evidenced by earlier literature such as Dahluqust and Robertson (2001); Kang and Stulz (1997) in Kalev (2008). 
While in terms of trade advantage, daily trading price analysis shows that local investors still have an advantage in their own short-term capital markets. This finding is related to the ambiguity bias which can cause investors to prefer companies that are geographically close to them and ignore investments that are apparently located far away from them.

Endowment Bias. The last is endowment bias. This is an emotional type of bias. Person who plays endowment bias judges an asset more when s/he holds property rights than does not hold it. Endowment bias is not inconsistent with standard economic theory in which the asset that a person wants to pay on an object must always be the same as the person's desire to accept the surrender of the object. When acceptance is taken into account in the form of compensation. Psychologists have found that the minimum sales price that people specify tends to exceed the maximum purchase price they want to pay on the same item. Endowment bias may affect attitudes toward self-owned items over long periods of time or may be brought up immediately as items obtained.

Endowment bias is described as a mental process, which comes from being placed against the value of an object. The value depends on whether an object's ownership is generated by its loss or whether it is one that the object does not own and has its potential result. If one loss of an object is one of the given, then an amount of the loss is received to be greater than the amount of the result obtained if the object is newly added to another endowment. According to Richard Thaler (in Phompian, 2006), endowment bias occurs when out-of-pocket costs are seen as a loss and opportunity costs are seen as a floating result, farmers will become heavier in accepting them. Furthermore, a certain level of the degree of the event is introduced in the consumer choice process because the goods included in the gift of the individual will become more valuable than those not included in grace.

The practical application of endowment bias can be seen in four investment options, i.e., moderate risk share, riskier shares, state secured securities, and local/city government securities. Another group of investors is to establish the same list of options. They imagine that they are ready to inherit a special item on the list. If interested, investors will say they will provide a derivative hypothesis supporting different options and will do so without penalties. Most wealth management practitioners have found clients who are reluctant to sell securities left behind by previous generations.

In the long term, local excellence helps local investors to provide better performance than the foreign in most shares, except for Nokia shares, as these international shares are listed in cross exchange and the ownership is about $90 \%$ of foreign ownership. In contrast, in the ambiguity bias, it is evident that foreign investors can only use their superior investment proficiency in their long-term advantage as long as the share is known as an international share such as Nokia. The result is striking even though there is only one share used as a sample and it becomes a major consideration in distinguishing share characteristics over the rest of the shares from 35 samples at Helsinki Stock Exchange, Finland.

Distribution of Investors. In addition, foreign investors are particularly dominant in Indonesia's capital market. Indonesia's capital market growth is still dominated by foreigner investors. This can be seen from the funds of foreign investors entering the capital market reached up to Rp 54 trillion. An amount of funds is a challenge for domestic investors. In terms of ownership, of the total shares traded at foreign investors share still have about 64 percent. Besides, uneven spread of investors becomes one of the challenges of Indonesia's capital market in the future. So far, most players in the capital market are domiciled in Jakarta and surrounding areas. "Investors are still concentrated in Great Jakarta. This is a challenge for all how to increase the number of domestic investors with approaches of outside Java. The number of domestic investors is not optimal yet. Currently the number of investors in Indonesia's capital market is still very small, which is about 0.2 percent of the 230 million people of Indonesia (BEI, 2014). Since the unbalanced of foreign and domestic investment and the number of domestic investors compared to the foreign, resulting in Indonesia's capital market is very sensitive to the movement of foreign investors. Therefore, the role of domestic investors is necessary for Indonesia's capital market to stabilize, and the role of fund manager to have a program in order to increase the number of investors. Thus, 
in order to increase public participation in financial market especially in capital market, then capital market socialization in campus and community needs to be improved again.

Conclusion. Behavioral finance is a new approach that studies financial reality by incorporating the psychological dimension of investment. Based on the four research results synthesized here, each researcher has a different perspective on why foreign investors can be defeated by domestic investors. Foreign investors are less than the domestic because foreign investors are more aggressive, making them less patient in buying and selling stocks. Another finding is that domestic investors' performance is better than the foreign because domestic investors have information advantages compared to the foreign and bad poor timing, and it can also be attributed to asymmetric information between local investors and foreign investors caused by home bias, where domestic investors have fewer obstacles in accessing domestic company data about company-specific information except global shares.

With regard to behavioral bias, discrepancy of the findings above is certainly strongly influenced by the various behavioral biases occurring in capital markets such as selfattribution bias, illusion of control bias, conservative bias, ambiguity of aversion bias, and endowment bias. Much of the behavioral bias is closely related to the nature of investors as human beings where investment decision-making is influenced by their financial behavior, and unequal distribution of investors that are still concentrated in large cities only.

\section{REFERENCES}

1. Agarwal, S., Sheri Faircloth, C. Liu, dan Ghon Rhee, (2009), Why Do Foreign Investors Underperform Domestic Investors in Trading Activities? Evidence from Indonesia, Journal of Financial Markets, Volume 12, Februari, p. 32 - 53.

2. Asri, Marwan. 2013. Keuangan Keperilakuan, Edisi Pertama, Cetakan Pertama, Juni, BPFE UGM, Yogyakarta

3. Bursa Efek Indonesia (2014), 9th Annual Capital Market Outlook 2014 City Securities and Fund Services, Indonesia, BEl-Jakarta, Indonesia.

4. Choe, H., Kho, B.C., dan Stulz, (2005), Do Domestic Investors an Edge? The Trading Experience of Foreign Investors in Korea, Review of Financial Studies, Volume 18, p. $795-829$.

5. Dvorak, T., (2005), Do Domestic Investors Have an Information Advantage? Eviden from Indonesia, Journal of Finance, Volume 60, p.817 - 839.

6. Kahneman, D., Amos Tversky. 1979. Prospect Theory: An Analysis of Decision under Risk, Ekonometrica, Vol. 47, pp.263-291.

7. Kalev, Petko S., Anh H. Nguyen, dan Natalie Y. Oh., (2008), Foreign versus Local Investor: Who Knows more? Who makes more? Journal of Banking and Finance, Volume 32, pp.2376 - 2389.

8. Pompian, Michael M., (2006), Behavioral Finance and Wealth Management: How to Build Optimal Portfolios That Account for Investor Biases, John Wiley and Son Inc., USA.

9. Seasholes, M.S. 2000. Smart Foreign Traders Emerging Markets, Working Paper, Harvard University, January 31, 2000. P.1-24.

10. Schinckus, Christophe, (2011), Archeology of Behavioral Finance, The IUP Journal of Behavioral Finance, Vol. VIII, No.2.

11. Wendy, 2012. Pengaruh Perilaku Myopia pada Proses Pengambilan Keputusan Investasi dalam Eksperimen Laboratori: Implikasi Teori Myopic Loss Aversion di Pasar Modal, Kertas Kerja, Fakultas Ekonomi Universitas Tanjung Pura, Pontianak. 